\title{
Retrograde influence of muscle fibers on their innervation revealed by a novel marker for slow motoneurons
}

\section{Citation}

Chakkalakal, J. V., H. Nishimune, J. L. Ruas, B. M. Spiegelman, and J. R. Sanes. 2010.

"Retrograde Influence of Muscle Fibers on Their Innervation Revealed by a Novel Marker for Slow Motoneurons." Development 137 (20): 3489-99. doi:10.1242/dev.053348.

\section{Permanent link}

http://nrs.harvard.edu/urn-3:HUL.InstRepos:41543073

\section{Terms of Use}

This article was downloaded from Harvard University's DASH repository, and is made available under the terms and conditions applicable to Other Posted Material, as set forth at http:// nrs.harvard.edu/urn-3:HUL.InstRepos:dash.current.terms-of-use\#LAA

\section{Share Your Story}

The Harvard community has made this article openly available.

Please share how this access benefits you. Submit a story.

Accessibility 


\title{
Retrograde influence of muscle fibers on their innervation revealed by a novel marker for slow motoneurons
}

\author{
Joe V. Chakkalakal ${ }^{1}$, Hiroshi Nishimune ${ }^{1,2}$, Jorge L. Ruas ${ }^{3}$, Bruce M. Spiegelman ${ }^{3}$ and Joshua R. Sanes ${ }^{1, *}$
}

\begin{abstract}
SUMMARY
Mammalian limb and trunk skeletal muscles are composed of muscle fibers that differ in contractile and molecular properties. They are commonly divided into four categories according to the myosin heavy chain that they express: I, IIA, IIX and IIB, ranging from slowest to fastest. Individual motor axons innervate tens of muscle fibers, nearly all of which are of the same type. The mechanisms accounting for this striking specificity, termed motor unit homogeneity, remain incompletely understood, in part because there have been no markers for motoneuron types. Here we show in mice that the synaptic vesicle protein SV2A is selectively localized in motor nerve terminals on slow (type I and small type IIA) muscle fibers; its close relatives, SV2B and SV2C, are present in all motor nerve terminals. SV2A is broadly expressed at birth; fast motoneurons downregulate its expression during the first postnatal week. An inducible transgene incorporating regulatory elements from the Sv2a gene permits selective labeling of slow motor units and reveals their composition. Overexpression of the transcriptional co-regulator PGC1 $\alpha$ in muscle fibers, which converts them to a slow phenotype, leads to an increased frequency of SV2A-positive motor nerve terminals, indicating a fiber type-specific retrograde influence of muscle fibers on their innervation. This retrograde influence must be integrated with known anterograde influences in order to understand how motor units become homogeneous.
\end{abstract}

KEY WORDS: Fast muscle fiber, Motoneuron, Neuromuscular junction, SV2A, Slow muscle fiber, PGC1 $\alpha($ PPARGC1 $\alpha)$, Mouse

\section{INTRODUCTION}

A striking form of synaptic specificity, termed motor unit homogeneity, is evident in skeletal muscles. Muscle fibers can be divided into discrete types based on their metabolic, contractile and electrical properties; in rodent trunk and limb muscles, there are four types, called I, IIA, IIX, IIB, from slowest to fastest contracting, based on the myosin heavy chain (MyHC) gene that they express (Schiaffino and Reggiani, 1996). Each motor axon innervates many muscle fibers (generally a few dozen) within a single muscle, forming a motor unit. Remarkably, all or nearly all of the muscle fibers within a motor unit are of a single type (Burke, 1999). Motor unit homogeneity occurs even in muscles in which fibers of multiple types are intermingled (Edsgtrom and Kugelburg, 1968; Burke et al., 1973), indicating that it does not result from guidance of axons to appropriate target regions. Instead, it reflects selective matching of motor axons and muscle fibers.

How does motor unit homogeneity arise? Three mechanisms have been proposed. First, motor axons of predetermined types might innervate undifferentiated muscle fibers non-selectively, then induce them to express type-specific characteristics. Indeed, classic experiments of Buller et al. demonstrated that when a nerve that normally innervated a slow muscle was forced to innervate an immature muscle destined to become fast, the contractile properties of the muscle came to resemble those of a slow muscle, and vice versa (Buller et al., 1960). Later studies showed that cross-

\footnotetext{
${ }^{1}$ Department of Molecular and Cellular Biology and Center for Brain Science, Harvard University, 52 Oxford Street, Cambridge, MA 02138, USA. ${ }^{2}$ Department of Anatomy and Cell Biology, University of Kansas Medical School, Kansas City, KS 66160, USA. ${ }^{3}$ Dana-Farber Cancer Institute, Harvard Medical School, 44 Binney Street, Boston, MA 02115, USA.

*Author for correspondence (sanesj@mcb.harvard.edu)
}

Accepted 16 August 2010 reinnervation converted the molecular properties of the muscle fibers and revealed that the motor neuronal characteristic responsible for the transformation was its pattern of electrical activity: direct electrical stimulation of a muscle with patterns normally evoked by slow or fast nerves led to changes nearly as dramatic as those produced by cross-reinnervation (Ausoni et al., 1990; Windisch et al., 1998; Buonanno and Fields, 1999). Thus, initially non-selective innervation of muscle fibers by prespecified motoneurons can lead to motor unit heterogeneity by a conversion mechanism (Sanes and Yamagata, 2009).

Cross-reinnervation and electrical stimulation are, however, sometimes unable to completely convert muscle fiber properties (Dum et al., 1985; Westgaard and Lomo, 1988), suggesting that other factors are involved. Moreover, muscle fibers diversify to some extent in immature muscles, before innervation patterns are established, and even in muscles rendered aneural during development (Butler et al., 1982; Condon et al., 1990b; Wigmore and Evans, 2002). At least in chick embryos, motoneurons appear able to recognize regions rich in fibers of the appropriate type (Milner et al., 1998; Landmesser, 2001). Thus, a second possibility is that motoneurons and muscle fibers are each specified separately, and then become connected by a process of target recognition. Third, it is possible that muscle fibers play a role in determining the type-specific properties of the motoneurons that innervate them. In fact, cross-reinnervation studies of the sort used to reveal orthograde influences of innervation on muscles have also provided evidence for retrograde influences of muscles on the electrical properties of motoneurons (Foehring et al., 1987; Mendell et al., 1994; Munson et al., 1997). Finally, all three mechanisms might be involved: motoneuron and muscle fiber properties might be established independently, but bidirectional influences could adjust the phenotypes of the synaptic partners as motor units mature, leading to the high degree of homogeneity observed in adulthood. 
Studies of how motor unit homogeneity arises have been aided by the availability of markers for muscle fibers of different types, most notably antibodies specific for MyHC I, IIA, IIX or IIB (also known as MYH7, 2, 1 and 4, respectively - Mouse Genome Informatics) (Schiaffino and Reggiani, 1996). Conversely, a severe impediment to this analysis, and particularly to the investigation of retrograde influences on neuronal properties, has been the lack of molecular markers for fast or slow motoneurons (Kanning et al., 2010). As a first step in seeking such markers, we sought antibodies that labeled subsets of motor nerve terminals. We report here that the synaptic vesicle protein SV2A is selectively localized to motor nerve terminals on type I and a subset of type IIA muscle fibers. Using in situ hybridization and an inducible transgenic reporter, we demonstrate that this subtype-specific localization reflects selective expression of SV2A by slow motoneurons, which in turn arises by postnatal downregulation of SV2A expression in fast motoneurons. Use of the reporter line allowed us to prospectively identify and map slow motor units, leading to the identification of a novel motor unit type. Finally, we show that increasing the number of slow fibers in a muscle increases the number of SV2A-positive nerve terminals, providing evidence for a type-specific influence of muscle fibers on motoneuron properties. Taken together with previous studies of muscle fiber differentiation and its regulation by nerve-derived activity, these results suggest that retrograde and anterograde influences act together to promote motor unit homogeneity.

\section{MATERIALS AND METHODS}

\section{Animals}

A mouse BAC clone containing the $S v 2 a$ gene was obtained from Incyte Genomics (St Louis, MO, USA). This clone spanned $165 \mathrm{~kb}$ with the $S v 2 a$ gene located near the center. A recombineering method (Lee et al., 2001) was used to replace the segment between $78 \mathrm{bp}$ upstream and $496 \mathrm{bp}$ downstream of the initiator codon with a cDNA encoding tamoxifeninducible Cre recombinase T2 (CreER) (Feil et al., 1997). Transgenic mice harboring the recombined $\mathrm{BAC}$ clone were generated by oocyte injection and maintained on a C57/B6 background.

SV2ACreER mice were crossed to Thy1-STOP-YFP mice, which we generated previously (Buffelli et al., 2003). To activate CreER, $0.5 \mathrm{mg}$ tamoxifen $(50 \mu \mathrm{l}$ of a $10 \mathrm{mg} / \mathrm{ml}$ solution in 10:1 corn oil:ethanol) was injected intraperitoneally. MCK-PGC1 $\alpha$ transgenic mice were generated as described (Lin et al., 2002). Immune-deficient (SCID) mice were obtained from Jackson Laboratories (\#001303). Experiments on wild-type mice used C57/B6 and CD-1 animals interchangeably; no differences between these strains were noted.

\section{Histology \\ Antibodies}

Primary antibodies were anti-SV2A [AB15224 from Millipore and EGI916 from T. Sudhof, Stanford University (Janz and Sudhof, 1999)], anti-SV2B (EGI916 from T. Sudhof), anti-SV2C (U1129 from T. Sudhof), anti-MyHC I [A4840 from Developmental Studies Hybridoma Bank (DSHB) and NCLslow from Leica Microsystems/Novacastra Laboratories], anti-MyHC IIA (2F7 and SC-71 from DSHB), anti-pan MyHC except IIX (BF35 from DSHB), anti-MyHC IIB (BFF3 from DSHB), anti-actinin alpha 3 (Abcam) and anti-GFP (Millipore). Alexa-conjugated secondary antibodies and $\alpha$ bungarotoxin (BTX) were from Invitrogen.

\section{Cross-sections}

Muscles were dissected, rinsed in phosphate-buffered saline (PBS) pH 7.4, embedded in Tissue Freezing Medium (Electron Microscopy Sciences), frozen in melting 2-methyl butane in liquid nitrogen, and cross-sectioned at $8 \mu \mathrm{m}$ on a cryostat. Sections were allowed to thaw for 5 minutes and subsequently blocked with $1 \%$ normal goat serum, $4 \%$ bovine serum albumin and $0.1 \%$ Triton $\mathrm{X}-100$ (GAT) for 1 hour. Sections were then stained with primary antibodies overnight at $4{ }^{\circ} \mathrm{C}$ followed by incubation with secondary antibodies and Alexa-conjugated BTX for 1 hour at room temperature, then mounted in Fluoro Gel (Electron Microscopy Sciences). Images were taken with an Apotome microscope $(40 \times$ objective, Zeiss) or a Fluoview1000 confocal microscope (1.45 NA objective lens, Olympus). Levels were adjusted in Photoshop (Adobe) and individual channels were combined to generate color images.

\section{Longitudinal sections}

Muscles were dissected, rinsed in PBS, fixed in $4 \%$ paraformaldehyde (PFA) in PBS for 1 hour, incubated in $30 \%$ sucrose at $4{ }^{\circ} \mathrm{C}$ overnight, and frozen as above. Longitudinal sections were cut at $12 \mu \mathrm{m}$, refixed in methanol at $-20^{\circ} \mathrm{C}$ for 10 minutes, and blocked for 1 hour in GAT. Sections were then stained, imaged and analyzed as described above.

\section{Whole-mounts and vibratome sections}

Mice were perfused with $4 \%$ PFA, then muscles were isolated, post-fixed in ice-cold 2\% PFA for 30 minutes at $4{ }^{\circ} \mathrm{C}$, and blocked overnight in GAT plus $0.1 \mathrm{M}$ glycine and $0.02 \%$ sodium azide. Muscles were then incubated for 1 day each with primary antibodies and secondary antibody plus Alexaconjugated BTX. After washing in PBS, muscles were mounted in Vectashield and confocal stacks were obtained on a Fluoview1000 using a $60 \times$ objective. The stacks were examined and images processed using Imaris software (Bitplane). Spinal cords and brains were dissected from SV2ACreER;Thy1-STOP-YFP mice, embedded in agarose and sectioned with a vibratome.

\section{In situ hybridization}

Methods for in situ hybridization were described previously (Nishimune et al., 2005; Yamagata et al., 2002) using 5-bromo-4-chloro-3-indolylphosphate/nitroblue tetrazolium or the tyramide signal amplification system (TSA Plus system; PerkinElmer, Wellesley, MA, USA). Digoxygenin-labeled RNA antisense probes were generated using mouse cDNA fragments obtained by RT-PCR: Sv2a, 448-1491 bp of NM_022030.3; Sv2b, 746-1460 bp of NM_001109753.1; and Sv2c, 433-1482 bp of NM_029210.1. Following fluorescent in situ hybridization, sections were stained with goat anti-choline acetyltransferase (Millipore Bioscience Research Reagents).

\section{Motor unit reconstruction}

Mice were perfused with $1 \%$ sodium nitrite followed by $2 \%$ PFA. Muscles were screened for YFP-positive axons under a dissecting microscope equipped with fluorescence optics, then rinsed with PBS, post-fixed in $1 \%$ PFA for 15 minutes, blocked in GAT, and incubated in primary antibodies overnight. They were then washed with PBS, incubated with secondary antibodies overnight, washed again, incubated with Alexa-conjugated BTX for 2 hours, washed, soaked in Vectashield and mounted. In some instances, muscles were bleached overnight in Dent's Bleach $(50 \%$ methanol, $10 \%$ DMSO, $15 \% \mathrm{H}_{2} \mathrm{O}_{2}$ ) prior to incubation with primary antibodies, and cleared using methyl salicylate after dehydration in a graded ethanol series prior to mounting. Confocal stacks were obtained as above using $20 \times$ or $40 \times$ objectives. Images were analyzed and converted to tiff files using Imaris. Whole images were level adjusted, combined to generate color images, and cropped in Photoshop (Adobe).

\section{Adenovirus-mediated expression of PGC1 $\alpha$}

Recombinant adenovirus expressing an N-terminal Flag-fusion of mouse PGC1 $\alpha$ or GFP was generated using the pAdTrack system (Addgene). PGC1 $\alpha$ or GFP viral stock $\left(10 \mu 1,2 \times 10^{10}\right.$ infectious particles) was injected into the lower limbs in the vicinity of the plantaris. Eleven days after injection, whole lower limbs were isolated, fixed in ice-cold 4\% PFA, and incubated in $30 \%$ sucrose overnight at $4{ }^{\circ} \mathrm{C}$. Posterior crural muscles were processed for immunohistochemistry as described above.

\section{RESULTS \\ SV2A is concentrated in slow motor nerve terminals}

We began this study by seeking molecules present in subsets of motor nerve terminals. We stained transverse sections of adult mouse lower limb muscles with a panel of antibodies to proteins known to be present in nerve terminals, including neuropeptides, 

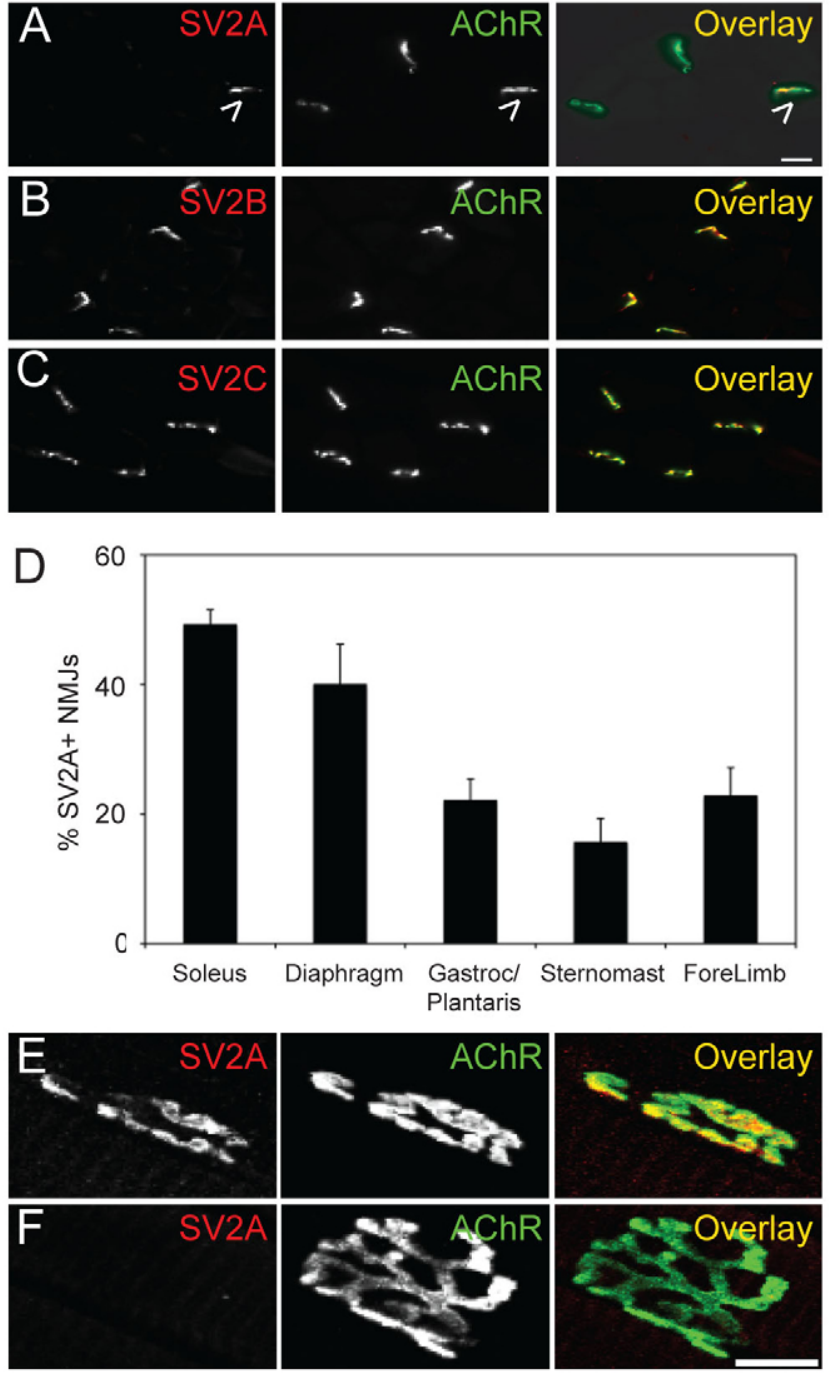

Fig. 1. SV2A is localized to a subset of motor nerve terminals. (A-C) Cross-sections of medial gastrocnemius stained with antibodies specific for SV2A, B or C plus $\alpha$-bungarotoxin (BTX) to mark synaptic sites (acetylcholine receptors, AChR). Nearly all synaptic sites bear SV2B and $C$, but only a subset is SV2A positive. Arrowheads in A indicate an SV2A-positive neuromuscular junction (NMJ). (D) Fraction of NMJs positive for SV2A in soleus, diaphragm, gastrocnemius/plantaris, sternomastoid and forelimb muscles. 100-250 NMJs from four mice were scored per muscle or muscle group. Bars indicate s.e.m.

$(\mathbf{E}, \mathbf{F})$ Whole-mount of triangularis sterni muscle labeled for SV2A and BTX. NMJs positive (E) and negative (F) for SV2A. Scale bars: $20 \mu \mathrm{m}$ in $C$ for $\mathrm{A}-\mathrm{C} ; 10 \mu \mathrm{m}$ in $\mathrm{F}$ for $\mathrm{E}, \mathrm{F}$.

ion channels and proteins involved in synaptic vesicle turnover and release. To identify synaptic sites, sections were counterstained with fluorescently conjugated $\alpha$-bungarotoxin (BTX), which binds specifically to acetylcholine receptors in the postsynaptic membrane. We found that the intrinsic synaptic vesicle protein SV2A was localized at a minority of synaptic sites (Fig. 1A). Similar results were obtained in several limb and trunk muscles, although the fraction of neuromuscular junctions (NMJs) labeled varied among muscles (Fig. 1D). Antibodies specific for the other two isoforms of SV2, SV2B and SV2C (Janz and Sudhof, 1999), stained most, if not all, NMJs in all muscles tested (Fig. 1B,C; data not shown). Because cross-sections include only part of each NMJ, we also analyzed whole-mounts and longitudinal sections to assess whether SV2A was present in restricted portions of many terminal arbors or in the entirety of a subset of arbors. SV2A stained the entirety of a subset of motor nerve terminals (Fig. 1E,F).

To determine whether SV2A-positive motor nerve terminals were apposed to a specific fiber type, we triply stained muscles with BTX plus antibodies to SV2A and to MyHC isotypes. Over $90 \%$ of nerve terminals on type I muscle fibers in posterior crural muscles of the lower limb (soleus, plantaris, lateral and medial gastrocnemius) were SV2A positive (Fig. 2A,B,I). By contrast, few terminals on type IIX or IIB fibers (less than $5 \%$ ) contained detectable SV2A (Fig. 2E-I). Type IIA muscle fibers displayed an intermediate pattern, with $\sim 40 \%$ of IIA fibers bearing SV2Apositive NMJs (Fig. 2C,D,I).

We next sought differences between type IIA muscle fibers bearing SV2A-positive and -negative NMJs. Molecular markers reported to subdivide type IIA fibers, such as myosin light chains (Wada and Pette, 1993), did not distinguish between fibers with SV2A-postive and -negative NMJs (data not shown). However, measurement of cross-sectional area revealed that type IIA muscle fibers with SV2Apositive NMJs were significantly smaller than SV2A-negative NMJs (Fig. 2K). Indeed, type IIA fibers with SV2A-positive NMJs were as small as type I fibers. Thus, SV2A is concentrated in the nerve terminals of most type I slow oxidative muscle fibers and in a subset of small-caliber type IIA fatigue-resistant muscle fibers.

To assess whether SV2A marked slow motor nerve terminals generally, we analyzed a variety of limb and trunk muscles, including masseter, triceps brachi, diaphragm, intercostals, rectus femoris, vastus lateralis, tibialis anterior and triangularis sterni. In all cases, SV2A was localized to NMJs on most type I muscle fibers and on a minority of type II muscle fibers (data not shown). In the white (fast) regions of the triceps brachi, vastus lateralis and masseter muscles, which contain few, if any, type I fibers (Delp and Duan, 1996), we found few, if any, SV2A-positive nerve terminals (data not shown). More detailed studies of the diaphragm demonstrated that, as in the hind limb, SV2A marked NMJs on most type I fibers, on small type IIA fibers, and on few type IIX or IIB fibers (Fig. 2J,L).

\section{Selective SV2A localization arises by postnatal loss from fast nerve terminals}

SV2A might be selectively associated with slow motor nerve terminals as they develop, it might appear later, or it might be broadly distributed at first and then selectively lost from fast motor nerve terminals. To distinguish among these possibilities, we stained cross-sections of developing and adult muscles with BTX plus isoform-specific antibodies to SV2. At birth, most nerve terminals contained all three isoforms of SV2 (Fig. 3A,D,G). SV2A was progressively lost from the majority of NMJs over the first postnatal month, whereas nearly all NMJs retained SV2B and SV2C into adulthood (Fig. 3D-J). Triple labeling with antibodies to $\mathrm{MyHC}$ isoforms confirmed that both type I and type II muscle fibers bore SV2A-positive NMJs at postnatal day (P) 5, then SV2A was selectively lost from type II muscle fibers as development proceeded (Fig. 3K). As noted above, the SV2A-positive nerve terminals on adult type II fibers were predominantly on type IIA fibers (data not shown).

\section{Selective SV2A localization reflects selective SV2A expression}

To determine whether restriction of SV2A to slow nerve terminals reflected selective expression of SV2A by a subset of motoneurons, we performed in situ hybridization on lumbar spinal cord with 

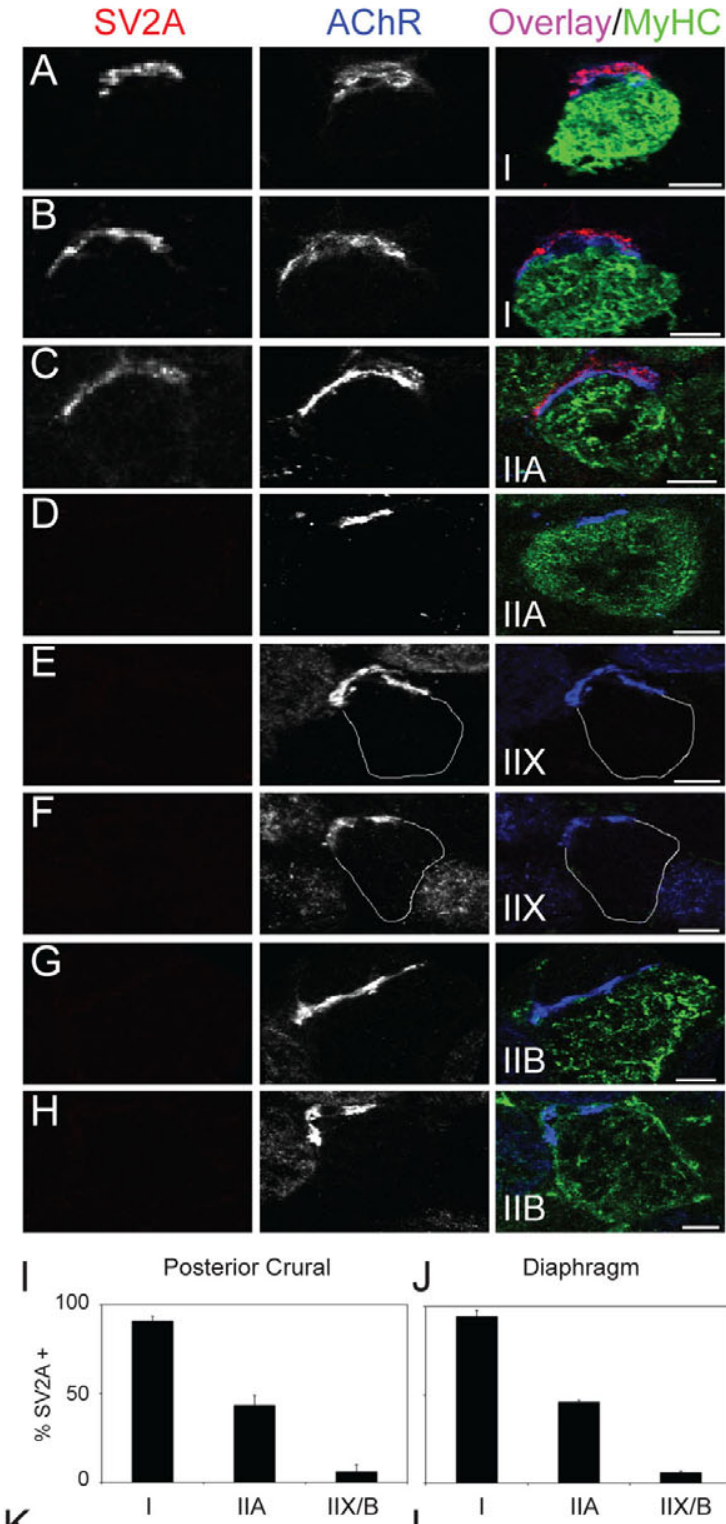

J Diaphragm

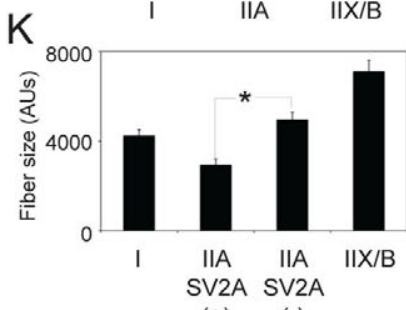

$(+) \quad(-)$

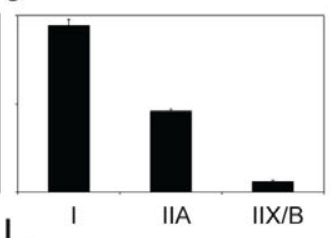

L

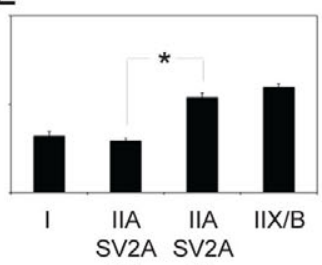

$(+) \quad(-)$

Fig. 2. SV2A marks type I and small type IIA motor nerve terminals. (A-H) Cross-sections of mouse hind-limb muscle triply stained with BTX plus antibodies to SV2A and myosin heavy chain (MyHC) isoforms. Type IIX fibers (indicated by lines in E,F) were identified as those that remained unlabeled by a combination of antibodies to MyHC I, IIA and IIB. Most type I (A,B), some type IIA (C,D) and a few type IIX or IIB (E-H) fibers bear SV2A-positive nerve terminals. Scale bars: $10 \mu \mathrm{m}$. (I,J) Fraction of type I, IIA and IIB or IIX muscle fibers in posterior crural (I) and diaphragm (J) muscles that bear SV2A-positive nerve terminals. Bars show mean \pm s.e.m. of counts from 585 NMJs in 13 limbs and 583 NMJs in 12 hemi-diaphragms. (K,L) Cross-sectional areas of muscle fibers in posterior crural $(\mathrm{K})$ and diaphragm $(\mathrm{L})$ muscles, classified by fiber type and whether or not they bore an SV2A-positive NMJ. ${ }^{*} P<0.0005$, paired $t$-test. probes specific for $S v 2 a, S v 2 b$ and $S v 2 c$. Motoneurons were identified by their large size and ventral position and by counterstaining with antibodies to choline acetyltransferase. $S v 2 a$, $S v 2 b$ and $S v 2 c$ were all expressed by a variety of neuronal types in both dorsal and ventral spinal cord, and in each case motoneurons were among the most intensely labeled. However, whereas most or all of the putative motoneurons expressed $S v 2 b$ and $S v 2 c$, only a small fraction of such cells expressed $S v 2 a$ (Fig. 4A-E). In the lumbar region of adult spinal cord, for example, 35\% (34/96 neurons from three mice) of choline acetyltransferase-positive motoneurons expressed $S v 2 a$, whereas $100 \%$ expressed $S v 2 c$. In general, $S v 2 a$-expressing motoneurons were smaller than their $S v 2 a$-non-expressing, choline acetyltransferase-positive neighbors (Fig. 4D), consistent with previous reports showing that slow motoneurons are smaller than fast motoneurons (Copray and Kernell, 2000; Kanning et al., 2010).

Based on these results, we devised a genetic strategy to label SV2A-positive motor axons and nerve terminals. Briefly, we generated transgenic mice in which a tamoxifen-regulated derivative of Cre recombinase, CreER, was expressed under the control of regulatory elements from the $S v 2 a$ gene (see Materials and methods). These mice were mated to a previously characterized line, Thy1-STOP-YFP (Buffelli et al., 2003), in which YFP is expressed in motoneurons following Cre-mediated excision of sequences that block transcription and translation (Fig. 5A). As shown in Fig. S1 in the supplementary material, neurons in many central structures, including cortex, hippocampus and spinal cord, were labeled. Within spinal cord, subsets of motoneurons and interneurons were labeled, consistent with results from in situ hybridization (compare Fig. 4C with Fig. S1A in the supplementary material).

To assess selective labeling of slow motoneurons, we administered tamoxifen to double-transgenic mice (SV2ACreER;Thy1-STOP-YFP) at P8-10, then examined muscles 20-60 days later. Initial screening revealed that the number of labeled axons was low (often just a few dozen per animal), even following multiple injections of tamoxifen. This situation contrasted with that observed previously, using a different CreER line and the same reporter, in which most motoneurons were labeled following a single injection (Buffelli et al., 2003). Thus, recombination is inefficient in motoneurons of this line, for reasons that we do not understand. Nonetheless, we found several YFPpositive motor axons in muscles characterized by high proportions of type I and type IIA muscle fibers (diaphragm, soleus and red belly of the medial gastrocnemius), but only a single axon in a sizematched set of muscles characterized by high proportions of type IIX and type IIB fibers (extensor digitorum longus, lateral gastrocnemius and white belly of the medial gastrocnemius) (Delp and Duan, 1996; Talmadge et al., 2004) (data not shown). We labeled diaphragm muscles with antibodies to type I MyHC and determined the fraction of YFP-positive nerve terminals on type I muscle fibers. Approximately $70 \%$ of YFP-positive NMJs were on type I muscle fibers (Fig. 5B,D), even though only $20 \%$ of diaphragm muscle fibers are type I (Talmadge et al., 2004). We then asked whether the $30 \%$ of YFP-positive NMJs not on type I fibers were on type IIA fibers. The antibody to MyHC-IIA was unsuitable for staining whole-mounts, so we labeled muscles with a mixture of antibodies that stained type I, IIX and IIB muscle fibers, leaving the IIA fibers unstained. Many of the YFP-positive NMJs were on type IIA fibers; an example is shown in Fig. 5C. Together, these results indicate that the $S v 2 a C r e E R$ transgene selectively labels slow motoneurons. 
SV2A

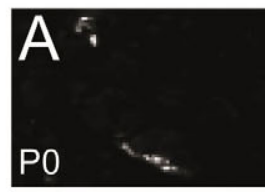

BTX/Overlay
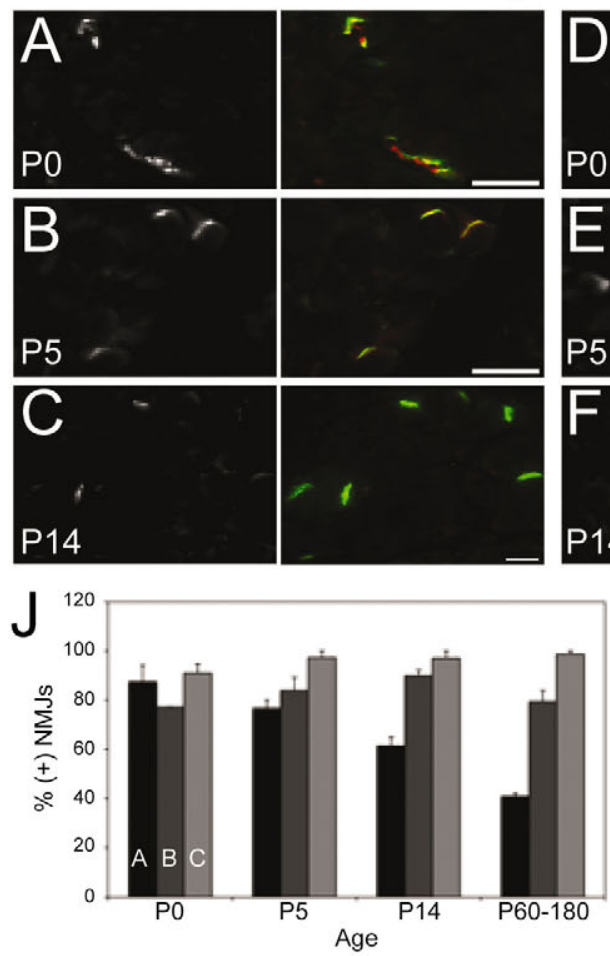

SV2B
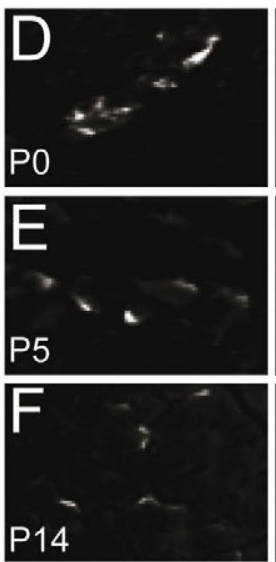

BTXIOverlay
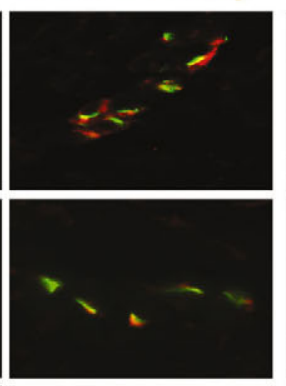

SV2C
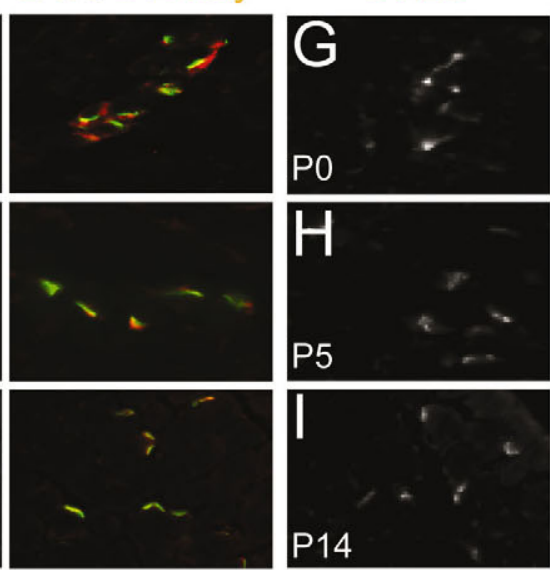

BTX/Overlay
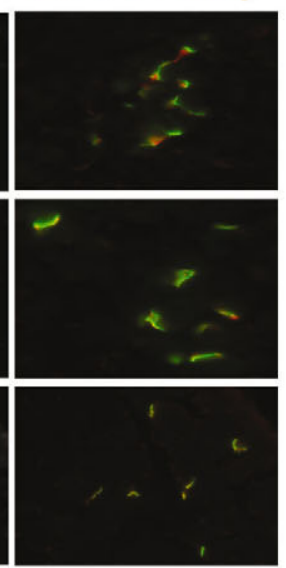

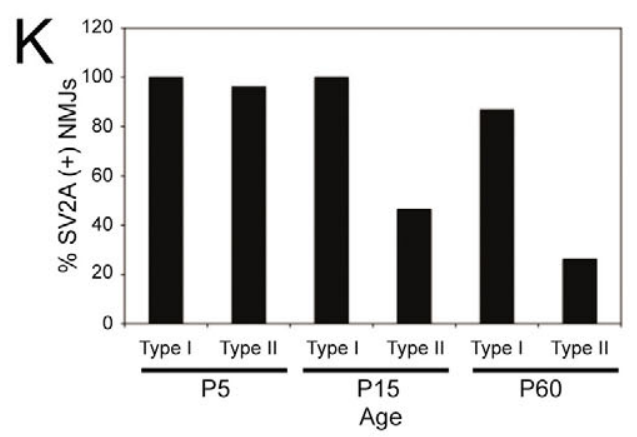

Fig. 3. SV2A is lost from fast motor nerve terminals postnatally. (A-I) Cross-sections of hind-limb muscle of the indicated ages stained with antibodies specific for SV2A, B or C plus BTX to mark synaptic sites. Nearly all P0 and P5 synaptic sites bear SV2A, B and C, but only a subset is SV2A positive in P14 hindlimbs. Scale bars: $20 \mu \mathrm{m}$. (J) Fraction of NMJs positive for SV2A, B or C in developing hindlimb and adult (2- to 6-monthold) posterior crural muscles. Each bar shows counts of 35-181 NMJs from two to five mice. Means differ significantly for SV2A P0 versus P14 $(P<0.05)$ and for P14 versus P60-180 ( $P<0.01)$. (K) Fraction of type I and type II NMJs positive for SV2A in P5, P15 lower limb and P60 adult posterior crural muscles. Each bar shows counts of 62-242 NMJs from two to seven mice.

To assess when SV2A expression becomes restricted to slow motoneurons, we performed in situ hybridization at P3 and injected double-transgenic mice with tamoxifen at P2 and P4, P5 and P7, or P8 and P10. In situ hybridization showed that most motoneurons in wild-type mice were both SV2A positive (27/35, or 77\%) and SV2C positive (19/19) at P3 (Fig. 4F,G). Similarly, NMJs labeled by injection of tamoxifen into double transgenics at P2-4 were randomly distributed between type I and II fibers (25\% labeled NMJs on type I fibers compared with $20 \%$ type I fibers in the muscle). Some selectivity was apparent by P5-7 (40\% of labeled NMJs on type I fibers) and, as noted above, selectivity was striking by P8-10 (Fig. 5D). Thus, Sv2a is downregulated in fast motoneurons during the first postnatal week.

\section{Transgenically marked slow motor units}

The ability to express YFP in slow motoneurons allowed us to reexamine the issue of motor unit homogeneity in a novel way. We injected tamoxifen into SV2ACreER;Thy1-STOP-YFP doubletransgenic mice at P8-10 then stained diaphragms with BTX plus antibodies to GFP (which cross-reacts with YFP) and type I MyHC. Automated confocal scanning was used to obtain highresolution images of YFP-positive axons and the muscle fibers they innervate. Fig. 6A shows a young motor unit, and Fig. 6B-J depicts the NMJs from this motor unit. Fig. 6K-N shows NMJs from another motor unit. Of nine motor units reconstructed, seven contained between nine and $14 \mathrm{NMJs}$, and in each case all, or all but one, of the NMJs was on a type I muscle fiber (Fig. 6O). These results support the conclusion that SV2A is selectively expressed by slow motoneurons. In addition, they provide direct support for fiber type homogeneity of slow motor units.

Interestingly, the other two motor units were larger than those of the first group (22 and 26 muscle fibers) and were not homogeneous, comprising a mixture of type I and type II muscle fibers (Fig. 6O). Attempts at quadruple labeling of these muscles (with BTX plus antibodies to GFP, MyHC I and MyHC IIA) were unsuccessful, but in view of the result that many SV2A-positive NMJs not on type I fibers are on type IIA fibers (Fig. 5D), we believe that most, or all, of the type II fibers in these motor units were type IIA. Because these mixed motor units were reconstructed at $\mathrm{P} 20$, it is possible that they were immature. For example, MyHC I-expressing fibers within them might also contain MyHC IIA (which was unstained), so gradual loss of MyHC I would result in a homogeneous type IIA motor unit. Alternatively, it is possible that these motor units are of a novel type, containing both type I and small type IIA fibers. Supporting the latter hypothesis, immunostaining revealed no diaphragm muscle fibers that coexpressed MyHC I and IIA after the end of the second postnatal week (data not shown). Moreover, of five motor units reconstructed from mature (P90) muscle, one contained a mixture of type I and II fibers (data not shown). 

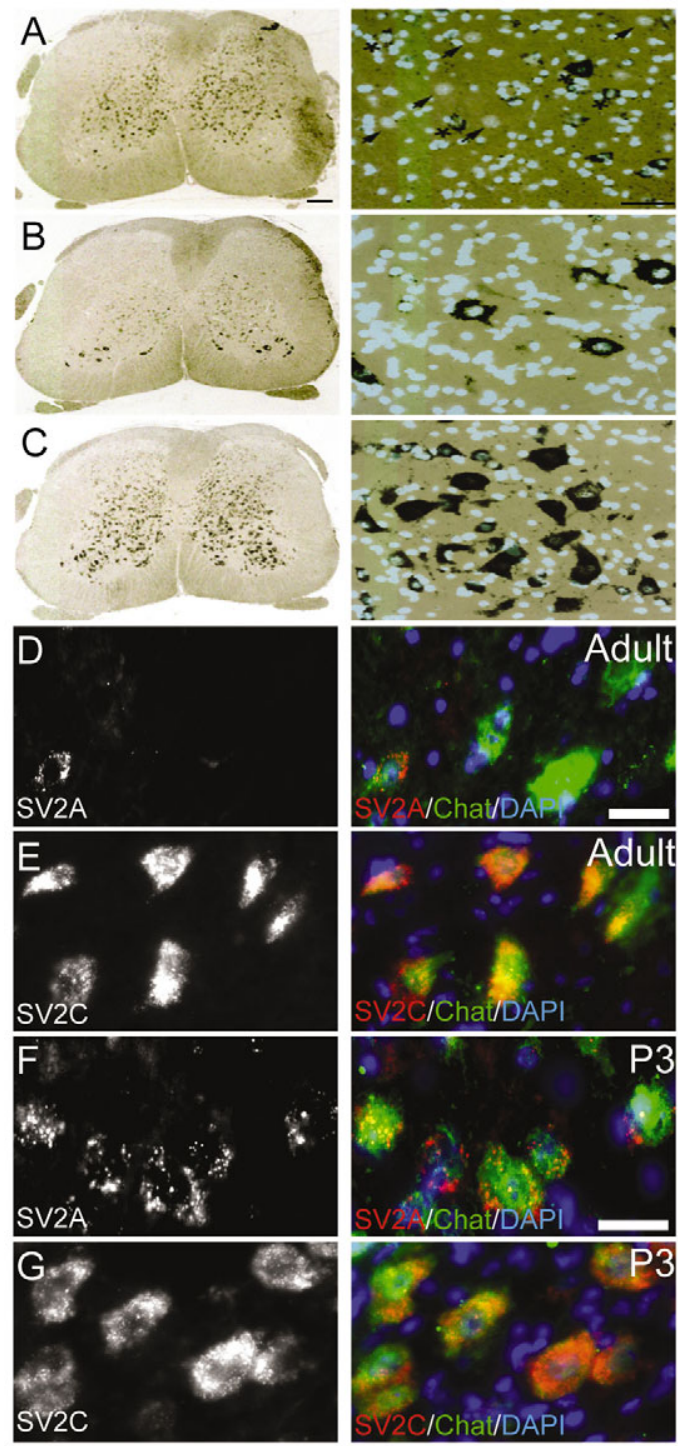

Fig. 4. SV2A is selectively expressed by fast motoneurons. (A-C) Cross-sections of lumbar spinal cord processed for in situ hybridization with probes specific for Sv2a, Sv2b and Sv2c. Right-hand panels show higher-magnification views of ventral horn counterstained with DAPI (blue) to show nuclei. Asterisks and arrows indicate motoneurons positive and negative, respectively, for Sv2a. (D-G) Crosssections of lumbar spinal cord from adult $(\mathrm{D}, \mathrm{E})$ or $\mathrm{P} 3(\mathrm{~F}, \mathrm{G})$ mice processed for fluorescent in situ hybridization for SV2a (D,F) or SV2C $(E, G)$, followed by immunohistochemistry for choline acetyltransferase (Chat) to identify motoneurons. Scale bars: $200 \mu \mathrm{m}$ in A-C (50 $\mu \mathrm{m}$ for the higher magnification views); $20 \mu \mathrm{m}$ in D-G.

\section{Overexpression of PGC1 $\alpha$ in muscle fibers leads to an increased incidence of SV2A-positive motor nerve terminals}

Results presented above indicate that SV2A is broadly expressed in motoneurons at birth, then becomes restricted to slow motoneurons during the first postnatal week. Previous studies (Narusawa et al., 1987; Condon et al., 1990a) and our own results (J.V.C. and J.R.S., unpublished) indicate that many muscle fibers acquire slow or fast characteristics at an earlier stage. This temporal sequence is consistent with the idea (Mendell et al., 1994) that retrograde influences from muscle fibers affect motoneuron
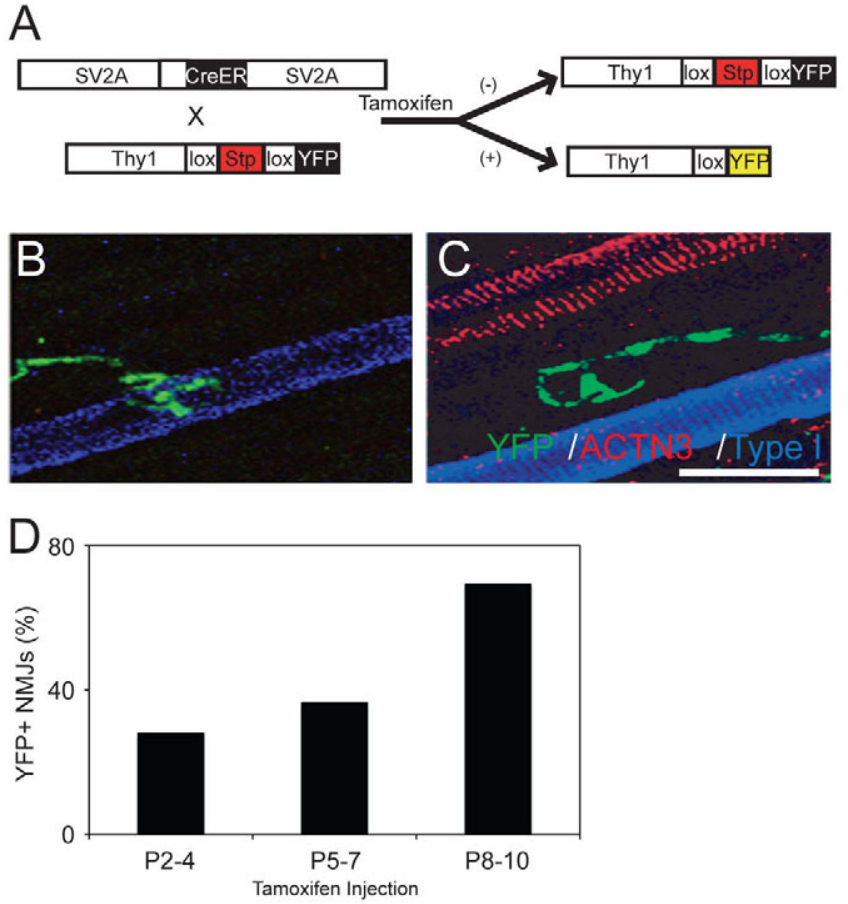

Fig. 5. SV2A expression by fast motoneurons is transcriptionally downregulated postnatally. (A) Schematic of transgenic strategy used to label slow motoneurons. SV2ACreER transgenic mice were crossed to Thy1-STP-YFP mice to derive SV2ACreER;Thy1-STP-YFP mice. Tamoxifen administration activates YFP expression in SV2ACreER;Thy1STP-YFP mice. (B,C) NMJs from adult SV2ACreER;Thy1-STP-YFP muscles labeled with antibodies to type I myosin (blue) and to actinin alpha 3 (red), which labels type IIX and IIB fibers. Unlabeled muscle fibers are therefore type IIA. Tamoxifen was administered at P10. NMJs in B and C are on type I and type IIA fibers, respectively. Scale bar: $20 \mu \mathrm{m}$.

(D) Fraction of YFP-labeled NMJs on type I slow muscle fibers after the injection of tamoxifen at P2 and P4 (164 NMJs from two mice), P5 and P7 (268 NMJs from five mice) or P8 and P10 (153 NMJs from six mice).

properties. To test this idea, we sought methods for increasing the number of slow muscle fibers in vivo without affecting motoneurons directly.

Recently, Lin et al. showed that the transcriptional co-activator PGC $1 \alpha$ (PPARGC1 $\alpha$ - Mouse Genome Informatics) is expressed at higher levels in predominantly slow muscles than in predominantly fast muscles and that ectopically expressing PGC1 $\alpha$ in fast muscles partially converts them to a slow phenotype (Lin et al., 2002). In the transgenic line they described, PGC1 $\alpha$ was expressed specifically in muscle, using regulatory elements that drive expression preferentially in fast fibers beginning in late fetal life. PGC1 $\alpha$ levels were elevated several fold in the predominantly fast plantaris muscle, bringing them to the same level as that seen in soleus muscle, which is composed entirely of type I and IIA fibers (Lin et al., 2002). Immunostaining of muscles from this transgenic line and littermate controls with antibodies to MyHC I, IIA, IIX and IIB confirmed a shift to a slower phenotype: the numbers of type I, IIA and IIX fibers increased at the expense of type IIB fibers (Fig. 7A$\mathrm{D}$; data not shown). As expected, transformation in fiber type was most striking in the plantaris muscle (data not shown), so we examined the NMJs of this muscle for the presence of SV2A. The proportion of SV2A-positive NMJs was more than 2-fold higher in the plantaris of PGC1 $\alpha$ transgenics than in littermate controls (Fig. 

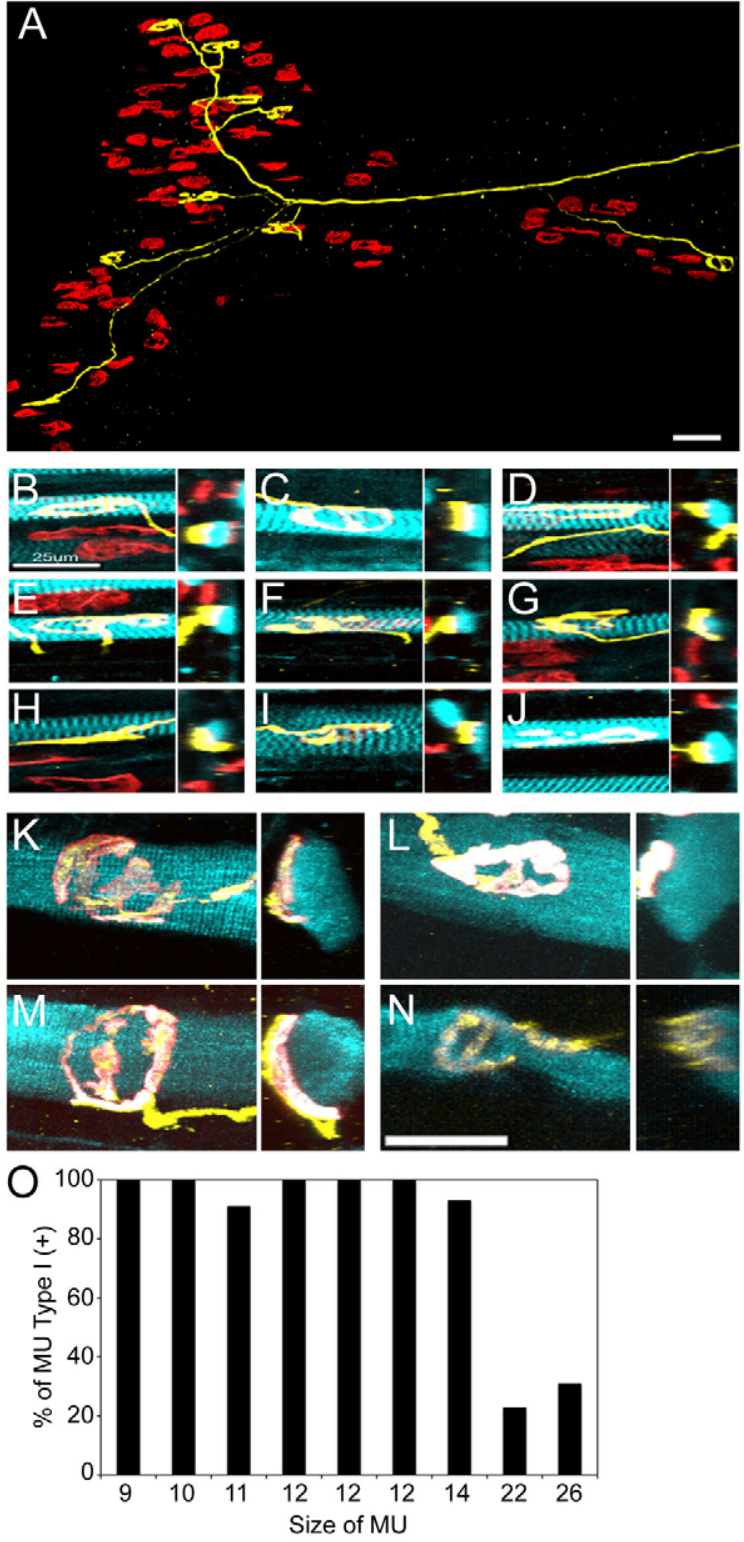

Fig. 6. SV2A-positive motoneurons form slow and mixed motor units. (A) Reconstructed motor unit from diaphragms of young SV2ACreER;Thy1-STP-YFP transgenic mice following tamoxifen administration at P8 and P10. Muscles were labeled with antibodies to YFP (yellow), BTX (red) and myosin type I (cyan). (B-J) Individual NMJs from the motor unit in A. (K-N) Individual NMJs from adult motor units. The left panel of each pair shows a confocal image and the right-hand panel shows a $90^{\circ}$ rotation. All NMJs are on type I muscle fibers. Scale bars: $50 \mu \mathrm{m}$ in $\mathrm{A} ; 25 \mu \mathrm{m}$ in B-N. (O) Fiber type composition and size of nine motor units reconstructed from SV2ACreER;Thy-STP-YFP diaphragms following tamoxifen injection at P8 and P10. Seven of the motor units contain all, or nearly all, type I fibers; the two largest motor units contain both type I and II fibers.

7E). Thus, a muscle-specific alteration in gene expression that increases the proportion of slow muscle fibers leads to an increased number of slow-type motor nerve terminals.

How might PGC1 $\alpha$ overexpression affect the number of SV2Apositive motor nerve terminals? Three possibilities are illustrated in Fig. 8. First, slow muscle fibers might generate retrograde
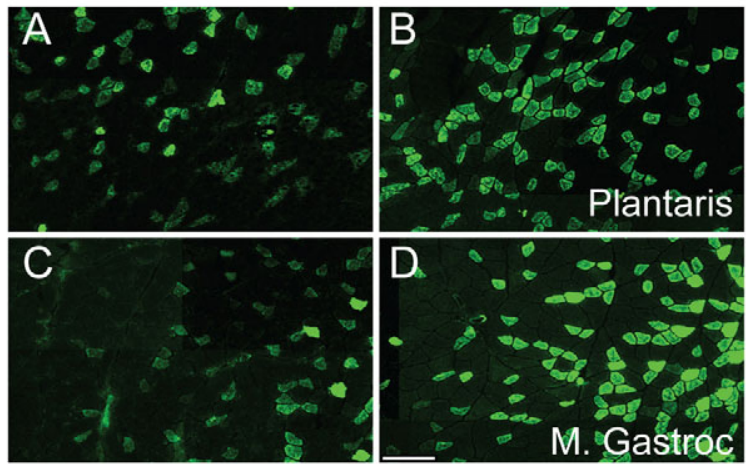

E
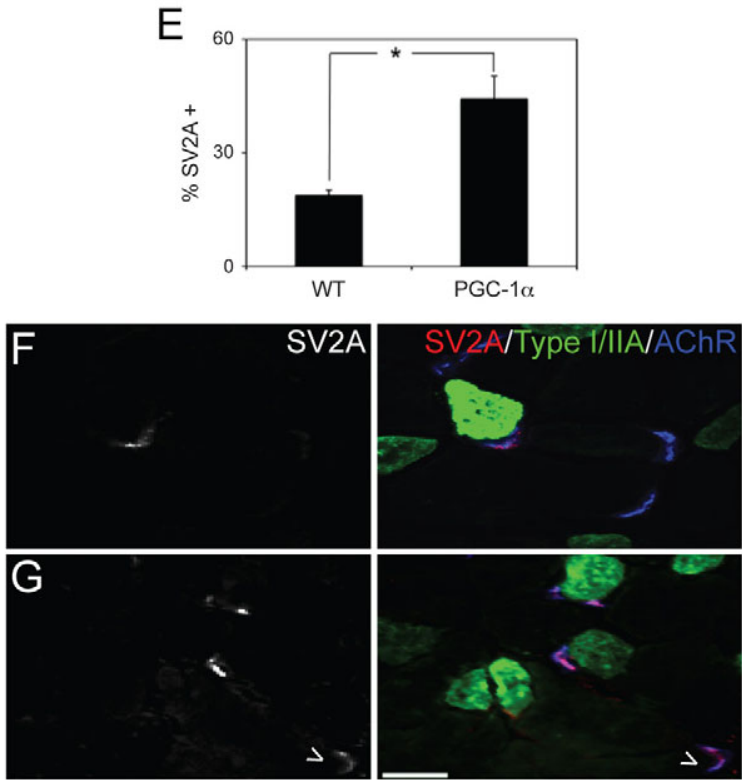

$\mathrm{H}$
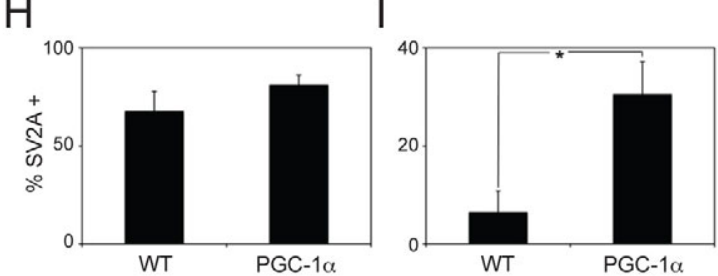

Fig. 7. Selective expression of PGC1 $\alpha$ in muscle fibers increases SV2A levels in motor nerve terminals. (A-D) Type I and IIA muscle fibers in plantaris $(A, B)$ and deep medial gastrocnemius $(C, D)$ muscles of wild-type $(A, C)$ and $P G C 1 \alpha$ transgenic $(B, D)$ mice. Scale bars: $100 \mu \mathrm{m}$ in A-D. (E) Fraction of NMJs that are SV2A positive in the plantaris of wild-type and PGC $1 \alpha$ transgenic mice. Data are from 108 NMJs from three wild-type mice and 120 NMJs from four transgenic mice. ${ }^{*} P<0.03$ by $t$-test. $(\mathbf{F}, \mathbf{G})$ Cross-section of wild-type $(\mathrm{F})$ and $\mathrm{PGC} 1 \alpha$ transgenic (G) plantaris labeled for antibodies that detect SV2A (red), BTX (blue) and type I and IIA myosin heavy chain. The arrowheads marks an SV2A-positive mismatched NMJ. (H,I) Fraction of NMJs on type I/IIA (H) or type IIX/IIB (I) muscle fibers that are SV2A positive in wild-type and PGC $1 \alpha$ transgenic plantaris. ${ }^{*} P<0.05, t$-test.

factors that promote the acquisition of slow characteristics in motoneurons that innervate them. If this were the case, some transformed motoneurons might form SV2A-positive nerve terminals on fast muscle fibers. Second, slow motoneurons might selectively maintain synapses on slow muscle fibers as supernumerary synapses are eliminated perinatally (Sanes and 


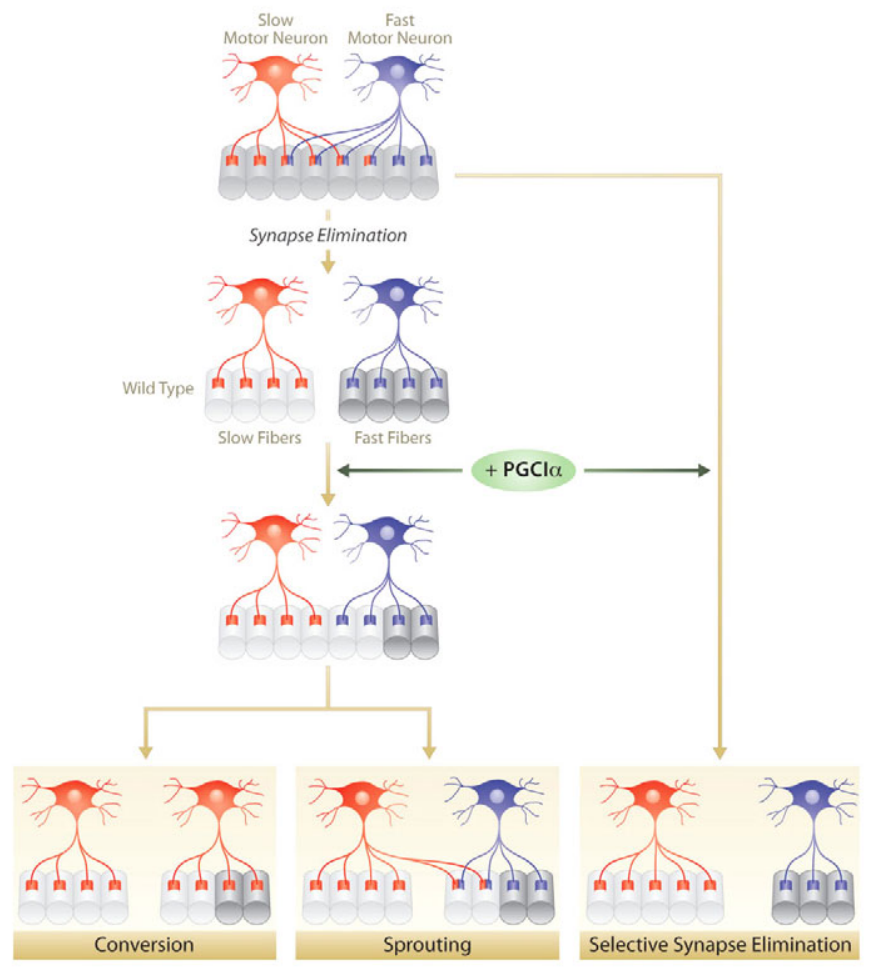

Fig. 8. Mechanisms accounting for increased numbers of SV2Apositive nerve terminals in PGC1 $\alpha$-overexpressing muscle.

Schematic of how selective synapse elimination, sprouting or retrograde signaling could lead to increased numbers of SV2A-positive nerve terminals following fiber type conversion. SV2A-positive motoneurons and nerve terminals and slow muscle fibers are white; SV2A-negative motoneurons and nerve terminals and slow muscle fibers are gray. Selective synapse elimination could occur only if fiber type conversion occurs prior to synapse elimination. Only retrograde signaling leads to a mismatch in which SV2A-positive nerve terminals abut type IIX or IIB muscle fibers.

Lichtman, 1999). If additional slow muscle fibers were present during synapse elimination, slow motoneurons would end up with larger motor units. Third, slow muscle fibers might be able to attract input from slow motoneurons. If this were the case, new slow fibers might be transiently or permanently innervated by both slow and fast motoneurons.

We performed two experiments to distinguish among these alternatives. First, we probed $S v 2 a$ expression in lumbar spinal cord from transgenic mice by in situ hybridization. The fraction of motoneurons expressing $S v 2 a$ was $60 \%$ ( $n=2$ mice) in transgenics compared with $35 \%$ (see above) in controls. Second, we labeled sections for both MyHC I and IIA along with SV2A, and compared the proportion of SV2A-positive nerve terminals on slow (I+IIA) and fast (unlabeled, IIX+IIB) fibers in PGC1 $\alpha$ transgenic and control plantaris (Fig. 7F-I). Most type I fibers bore SV2A-positive nerve terminals in both control and PGC1 $\alpha$ transgenic muscles, but the fraction of NMJs with SV2Apositive nerve terminals abutting fast muscle fibers was 5 -fold higher in transgenic than in control muscle (Fig. 7H,I). An increase in the incidence of such 'mismatched' NMJs is predicted to occur if motoneurons that initially innervated fast muscle fibers were transformed into slow motoneurons by factors released from a subset of their synaptic targets. Taken
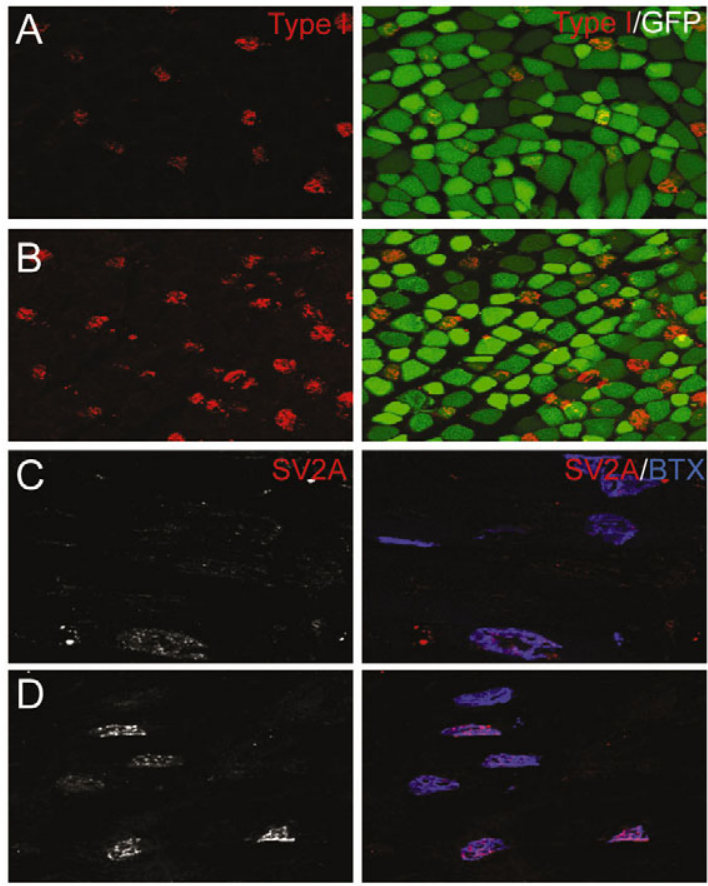

$\mathrm{E}$
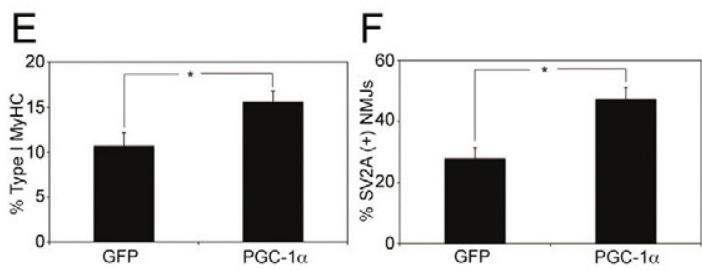

Fig. 9. Selective expression of PGC1 $\alpha$ in muscle fibers increases SV2A levels in motor nerve terminals. $(\mathbf{A}, \mathbf{B})$ Cross-section of

posterior crural muscles from mice infected with adenovirus expressing GFP (A) or GFP plus PGC $1 \alpha(B)$, labeled with antibody specific for type I $\mathrm{MyHC}$. (C,D) Longitudinal sections of posterior crural muscles from mice infected with adenovirus expressing GFP (A) or GFP plus PGC $1 \alpha$ (B), labeled with anti-SV2A and BTX. (E) Fraction of GFP-positive muscle fibers that are type I MyHC positive in posterior crural muscles from mice infected with adenovirus expressing GFP or GFP plus PGC $1 \alpha$. Each bar represents the mean \pm s.e.m. of counts from four mice (more than 1600 fibers). ${ }^{*} P<0.05$, $t$-test. (F) Fraction of GFP-positive muscle fibers that bear SV2A-positive nerve terminals in posterior crural muscles from mice infected with adenovirus expressing GFP or GFP plus PGC $1 \alpha$. Bars show mean \pm s.e.m. of counts from six mice (more than $250 \mathrm{NMJs}$ ). ${ }^{\star} P<0.05, t$-test.

together, these results indicate that slow muscle fibers promote or maintain the expression of $S v 2 a$ in motoneurons that would otherwise downregulate this gene.

Can signals from slow muscle fibers induce re-expression of SV2A in fast motoneurons after it has been downregulated? To test this possibility, we used an adenoviral vector to introduce PGC1 $\alpha$ into posterior crural muscles at P10. We chose this time because muscles become refractory to infection at later times (data not shown), and used immunocompromised (SCID) mice to avoid immune responses to adenoviral antigens. Virus encoding PGC1 $\alpha$ plus GFP was injected into one limb, and virus encoding only GFP was injected into the contralateral limb of the same animals. Eleven days later, muscles were stained for GFP, SV2A and BTX (Fig. 9). The number of type I fibers was increased in PGC1 $\alpha$ overexpressing muscles, indicating that $\mathrm{PGCl} \alpha$ can transform 
fibers that have already acquired type-specific properties (Fig. 9A,B,E). Importantly, the number of infected (GFP-positive) muscle fibers bearing SV2A-positive nerve terminals was higher in PGC1 $\alpha$-overexpressing than in control muscles (Fig. 9C,D,F). Because synapse elimination is nearly complete by P10 (Sanes and Lichtman, 1999), this increase cannot be explained by an effect on this process (Fig. 8, right). Instead, we conclude that motoneurons remain plastic and sensitive to retrograde influences for at least some period, and can reverse the decision to downregulate SV2A expression in response to muscle-derived signals.

\section{DISCUSSION}

Over recent years, numerous molecular differences have been discovered among motor pools, the cohorts of motoneurons that innervate individual muscles. These discoveries have enabled a penetrating analysis of how motor pools are specified and how they connect to their targets (Landmesser, 2001; Dalla Torre di Sanguinetto et al., 2008). In sharp contrast, little is known about molecular heterogeneity within motor pools, such as distinctions between motoneurons that innervate fast and slow muscle fibers. Consequently, it has been difficult to ascertain how motor unit homogeneity, a striking instance of synaptic specificity, is established. This report represents an attempt to address this limitation. Our main results are as follows. First, SV2A is selectively expressed by motoneurons that innervate slow (type I and small type IIA) muscle fibers, providing what is, to our knowledge, the first marker of slow motoneurons. Second, SV2A becomes restricted to slow motoneurons postnatally, indicating that motoneurons acquire at least some type-specific characteristics after they have already formed functional synapses. Third, increasing the number of slow muscle fibers in a muscle increases the number of SV2A-positive motor nerve terminals, suggesting the existence of retrograde signals from muscles that promote or stabilize type-specific motoneuron properties.

\section{SV2A marks slow motoneurons}

Intracellular recording has revealed differences between the electrical properties of fast and slow motoneurons, including their intrinsic excitability, input resistance, conduction velocity and afterhyperpolarization amplitude (Zengel et al., 1985). Analysis of synaptic transmission from nerve to muscle has demonstrated differences between the neurotransmitter release properties of the nerve terminals that fast and slow motoneurons form on muscle fibers (Gertler and Robbins, 1978; Reid et al., 1999). One might imagine that these physiological differences reflect molecular differences between slow and fast motoneurons in the expression of ion channels or components of the release apparatus. In addition, several studies have documented the presence of various neuropeptides in subsets of nerve terminals within a muscle, and the heterogeneous expression of growth factors and their receptors by motoneurons within a motor pool (Raivich et al., 1995; Copray and Kernell, 2000; Kanning et al., 2010). Moreover, molecular differences between alpha and gamma motoneurons (which innervate ordinary muscle fibers and muscle spindles, respectively) have been described recently (Friese et al., 2009).

Our limited screen failed to detect differences in channel expression among motoneurons, nor did we find patterns of neuropeptide localization that corresponded to fiber type distinctions. However, we found that SV2A is expressed by a subset of motoneurons, and that SV2A protein is selectively localized in motor nerve terminals on slow (type I and small type IIA) muscle fibers. $\mathrm{SV} 2$ is an intrinsic membrane protein that appears to be present in all synaptic vesicles (Bajjalieh et al., 1992; Feany et al., 1992; Takamori et al., 2006). Genetic analysis in mice has demonstrated that SV2 is required for normal synaptic transmission, possibly by playing a role in priming vesicles for calcium-dependent exocytosis (Janz et al., 1999; Custer et al., 2006; Chang and Sudhof, 2009). Its three closely related isoforms, SV2A, B and C, are encoded by separate genes and have distinct but overlapping expression patterns. In the brain, SV2A is present at most brain synapses, whereas SV2B and SV2C have more restricted distributions (Janz and Sudhof, 1999). In motoneurons, as demonstrated here, the pattern is different: SV2B and SV2C are broadly and SV2A narrowly distributed. It seems likely that the presence of SV2A in slow motoneurons is related to their tonic activity pattern, but to date no biophysical differences among SV2 isoforms have been detected that could help explain their role. Interestingly, the anti-epileptic drug levetiracetam modulates neurotransmitter release by binding specifically to SV2A (Lynch et al., 2004); it might be a useful reagent for probing the roles of this isoform at NMJs.

\section{Postnatal differentiation of slow motoneurons}

A cardinal characteristic of motor units is that the properties of the motoneuron are matched to those of the muscle fibers it innervates. For example, slow motoneurons release neurotransmitter tonically at low rates and slow muscle fibers contract slowly but are fatigue resistant; by contrast, fast motoneurons release neurotransmitter intermittently in high-frequency bursts and fast muscle fibers are fatigue susceptible but contract rapidly (Mendell et al., 1994). The precision of this coordination suggests that it is generated, or at least tuned, by interactions between neurons and muscle fibers. One way of judging which interactions might be important is to determine when motoneurons and muscle fibers acquire typespecific properties.

A common idea is that motoneurons become specified as fast or slow in embryos, then induce a corresponding identity in muscle fibers during early postnatal life (Buonanno and Fields, 1999; Wigmore and Evans, 2002). However, although there is evidence for metabolic heterogeneity among embryonic motoneurons (Huizar et al., 1975; Sheard et al., 1997), there is no direct evidence on when type-specific properties are acquired, and at least some diversification continues until the end of the first postnatal month, after motor patterns are established (Bewick et al., 2004). Our results indicate that one characteristic difference between fast and slow motoneurons - the restriction of SV2A expression to the latter - occurs during the first postnatal week. This conclusion was suggested by the postnatal loss of SV2A from fast motor nerve terminals; more direct evidence came from in situ hybridization and the use of SV2ACreER transgenic mice, in which timed administration of tamoxifen activated reporter expression broadly at P2, but selectively in slow muscles by P8. Thus, we speculate that signals sent to motoneurons during the first few postnatal days extinguish SV2A expression in fast motoneurons and/or preserve SV2A expression in slow motoneurons. Taken together with evidence that slow and fast muscle fibers acquire at least some of their distinguishing characteristics prenatally (Condon et al., 1990a; Wigmore and Evans, 2002), this temporal pattern is consistent with the idea that fast and/or slow muscle fibers emit retrograde signals that influence the type-specific properties of motoneurons.

\section{Retrograde signal from muscle to nerve}

To test the idea that slow muscle fibers provide a retrograde signal to the motoneurons that innervate them, we needed a marker for slow motoneurons and a means of manipulating the number of 
slow muscle fibers. SV2A provided the former and muscle-specific expression of $\mathrm{PGC} 1 \alpha$ provided the latter. We confirmed the finding that expression of PGC1 $\alpha$ induces a partial transformation of fast fibers to a slow phenotype (Lin et al., 2002), and found that this conversion led to an increased fraction of SV2A-positive NMJs. Further studies provided evidence that this increase reflected the conversion of nerve terminals to a slow (SV2A-positive) phenotype rather than an indirect effect of synaptic rearrangements, such as sprouting or withdrawal (Fig. 8).

The mechanism by which muscle fibers exert a type-specific effect on motoneurons remains to be determined. An attractive hypothesis is that slow muscle fibers secrete an instructive factor that travels retrograde to somata, where it alters patterns of gene expression. Such retrograde mechanisms have been studied in detail with respect to neurotrophins (Zweifel et al., 2005). In fact, the neurotrophin NT4 (NTF5 - Mouse Genome Informatics) is a promising candidate retrograde factor; it is selectively expressed by slow muscles and can induce both the growth of motor axons and the differentiation of muscle fibers (Funakoshi et al., 1995; Carrasco and English, 2003). In our hands, delivery of NT4 to developing muscle failed to affect the frequency of SV2A-positive nerve terminals (J.V.C. and J.R.S., unpublished). It remains possible, however, that NT4 is part of a multi-component signaling system, other components of which could be identified by comparing mRNAs or proteins of control and $\mathrm{PGCl} \alpha$ transgenic plantaris.

\section{Acknowledgements}

We thank K. T. Brannan, Renate Lewis, Debbie Pelusi and Monica Chu for assistance, Jean Livet and Ryan Draft for advice, T. C. Sudhof for antibodies, and N. A. Jenkins and N. G. Copeland for recombineering vectors. This work was supported by grants from the NIH to J.R.S. (NS19195 and NS59853) and B.M.S. (DK54477). J.V.C. was supported by a Tim E. Noel Fellowship in ALS from the CIHR. Deposited in PMC for release after 12 months.

\section{Competing interests statement}

The authors declare no competing financial interests.

\section{Supplementary material}

Supplementary material for this article is available at

http://dev.biologists.org/lookup/suppl/doi:10.1242/dev.053348/-/DC1

\section{References}

Ausoni, S., Gorza, L., Schiaffino, S., Gundersen, K. and Lomo, T. (1990).

Expression of myosin heavy chain isoforms in stimulated fast and slow rat muscles. J. Neurosci. 10, 153-160.

Bajialieh, S. M., Peterson, K., Shinghal, R. and Scheller, R. H. (1992). SV2, a brain synaptic vesicle protein homologous to bacterial transporters. Science 257, 1271-1273.

Bewick, G. S., Reid, B., Jawaid, S., Hatcher, T. and Shanley, L. (2004).

Postnatal emergence of mature release properties in terminals of rat fast- and slow-twitch muscles. Eur. J. Neurosci. 19, 2967-2976.

Buffelli, M., Burgess, R. W., Feng, G., Lobe, C. G., Lichtman, J. W. and Sanes, J. R. (2003). Genetic evidence that relative synaptic efficacy biases the outcome of synaptic competition. Nature 424, 430-434

Buller, A. J., Eccles, J. C. and Eccles, R. M. (1960). Interactions between motoneurones and muscles in respect of the characteristic speeds of their responses. J. Physiol. 150, 417-439.

Buonanno, A. and Fields, R. D. (1999). Gene regulation by patterned electrical activity during neural and skeletal muscle development. Curr. Opin. Neurobiol. $\mathbf{9}$ $110-120$

Burke, R. E. (1999). Revisiting the notion of 'motor unit types'. Prog. Brain Res. 123, 167-175

Burke, R. E., Levine, D. N., Tsairis, P. and Zajac, F. E., 3rd (1973). Physiological types and histochemical profiles in motor units of the cat gastrocnemius. $J$. Physiol. 234, 723-748.

Butler, J., Cosmos, E. and Brierley, J. (1982). Differentiation of muscle fiber types in aneurogenic brachial muscles of the chick embryo. J. Exp. Zool. 224, 65-80.

Carrasco, D. I. and English, A. W. (2003). Neurotrophin $4 / 5$ is required for the normal development of the slow muscle fiber phenotype in the rat soleus. J. Exp. Biol. 206, 2191-2200

Chang, W. P. and Sudhof, T. C. (2009). SV2 renders primed synaptic vesicles competent for $\mathrm{Ca}^{2+}$-induced exocytosis. J. Neurosci. 29, 883-897.
Condon, K., Silberstein, L., Blau, H. M. and Thompson, W. J. (1990a). Development of muscle fiber types in the prenatal rat hindlimb. Dev. Biol. 138 256-274.

Condon, K., Silberstein, L., Blau, H. M. and Thompson, W. J. (1990b). Differentiation of fiber types in aneural musculature of the prenatal rat hindlimb. Dev. Biol. 138, 275-295.

Copray, S. and Kernell, D. (2000). Neurotrophins and trk-receptors in adult rat spinal motoneurons: differences related to cell size but not to 'slow/fast' specialization. Neurosci. Lett. 289، 217-220.

Custer, K. L., Austin, N. S., Sullivan, J. M. and Bajjalieh, S. M. (2006). Synaptic vesicle protein 2 enhances release probability at quiescent synapses. J. Neurosci. 26, 1303-1313.

Dalla Torre di Sanguinetto, S. A., Dasen, J. S. and Arber, S. (2008) Transcriptional mechanisms controlling motor neuron diversity and connectivity. Curr. Opin. Neurobiol. 18, 36-43.

Delp, M. D. and Duan, C. (1996). Composition and size of type I, IIA, IID/X, and IIB fibers and citrate synthase activity of rat muscle. J. Appl. Physiol. 80, 261270

Dum, R. P., O'Donovan, M. J., Toop, J., Tsairis, P., Pinter, M. J. and Burke, R. E. (1985). Cross-reinnervated motor units in cat muscle. II. Soleus muscle reinnervated by flexor digitorum longus motoneurons. J. Neurophysiol. 54, 837851.

Edstrom, L. and Kugelberg, E. (1968). Histochemical composition, distribution of fibres and fatiguability of single motor units. Anterior tibial muscle of the rat. $J$. Neurol. Neurosurg. Psychiatry 31, 424-433.

Feany, M. B., Lee, S., Edwards, R. H. and Buckley, K. M. (1992). The synaptic vesicle protein SV2 is a novel type of transmembrane transporter. Cell 70, 861867

Feil, R., Wagner, J., Metzger, D. and Chambon, P. (1997). Regulation of Cre recombinase activity by mutated estrogen receptor ligand-binding domains. Biochem. Biophys. Res. Commun. 237, 752-757.

Foehring, R. C., Sypert, G. W. and Munson, J. B. (1987). Motor-unit properties following cross-reinnervation of cat lateral gastrocnemius and soleus muscles with medial gastrocnemius nerve. II. Influence of muscle on motoneurons. J. Neurophysiol. 57, 1227-1245.

Friese, A., Kaltschmidt, J. A., Ladle, D. R., Sigrist, M., Jessell, T. M. and Arber, S. (2009). Gamma and alpha motor neurons distinguished by expression of transcription factor Err3. Proc. Natl. Acad. Sci. USA 106, 13588-13593.

Funakoshi, H., Belluardo, N., Arenas, E., Yamamoto, Y., Casabona, A., Persson, H. and Ibanez, C. F. (1995). Muscle-derived neurotrophin-4 as an activity-dependent trophic signal for adult motor neurons. Science 268, 14951499.

Gertler, R. A. and Robbins, N. (1978). Differences in neuromuscular transmission in red and white muscles. Brain Res. 142, 160-164.

Huizar, P., Kuno, M. and Miyata, Y. (1975). Differentiation of motoneurones and skeletal muscles in kittens. J. Physiol. 252, 465-479.

Janz, R. and Sudhof, T. C. (1999). SV2C is a synaptic vesicle protein with an unusually restricted localization: anatomy of a synaptic vesicle protein family. Neuroscience 94, 1279-1290.

Janz, R., Goda, Y., Geppert, M., Missler, M. and Sudhof, T. C. (1999). SV2A and SV2B function as redundant $\mathrm{Ca}^{2+}$ regulators in neurotransmitter release. Neuron 24, 1003-1016.

Kanning, K. C., Kaplan, A. and Henderson, C. E. (2010). Motor neuron diversity in development and disease. Annu. Rev. Neurosci. 33, 409-440.

Landmesser, L. T. (2001). The acquisition of motoneuron subtype identity and motor circuit formation. Int. J. Dev. Neurosci. 19, 175-182.

Lee, E. C., Yu, D., Martinez de Velasco, J., Tessarollo, L., Swing, D. A., Court, D. L., Jenkins, N. A. and Copeland, N. G. (2001). A highly efficient Escherichia coli-based chromosome engineering system adapted for recombinogenic targeting and subcloning of BAC DNA. Genomics 73, 56-65

Lin, J., Wu, H., Tarr, P. T., Zhang, C. Y., Wu, Z., Boss, O., Michael, L. F., Puigserver, P., Isotani, E., Olson, E. N. et al. (2002). Transcriptional coactivator PGC-1 alpha drives the formation of slow-twitch muscle fibres. Nature 418, 797-801.

Lynch, B. A., Lambeng, N., Nocka, K., Kensel-Hammes, P., Bajjalieh, S. M., Matagne, A. and Fuks, B. (2004). The synaptic vesicle protein SV2A is the binding site for the antiepileptic drug levetiracetam. Proc. Natl. Acad. Sci. USA 101, 9861-9866.

Mendell, L. M., Collins, W. F., 3rd and Munson, J. B. (1994). Retrograde determination of motoneuron properties and their synaptic input. J. Neurobiol. 25, 707-721

Milner, L. D., Rafuse, V. F. and Landmesser, L. T. (1998). Selective fasciculation and divergent pathfinding decisions of embryonic chick motor axons projecting to fast and slow muscle regions. J. Neurosci. 18, 3297-3313.

Munson, J. B., Foehring, R. C., Mendell, L. M. and Gordon, T. (1997). Fast-toslow conversion following chronic low-frequency activation of medial gastrocnemius muscle in cats. II. Motoneuron properties. J. Neurophysiol. 77 2605-2615. 
Narusawa, M., Fitzsimons, R. B., Izumo, S., Nadal-Ginard, B., Rubinstein, N. A. and Kelly, A. M. (1987). Slow myosin in developing rat skeletal muscle. J. Cell Biol. 104, 447-459.

Nishimune, H., Bernreuther, C., Carroll, P., Chen, S., Schachner, M. and

Henderson, C. E. (2005). Neural adhesion molecules L1 and CHL1 are survival factors for motoneurons. J. Neurosci. Res. 80, 593-599.

Raivich, G., Reddington, M., Haas, C. A. and Kreutzberg, G. W. (1995) Peptides in motoneurons. Prog. Brain Res. 104, 3-20.

Reid, B., Slater, C. R. and Bewick, G. S. (1999). Synaptic vesicle dynamics in rat fast and slow motor nerve terminals. J. Neurosci. 19, 2511-2521.

Sanes, J. R. and Lichtman, J. W. (1999). Development of the vertebrate neuromuscular junction. Annu. Rev. Neurosci. 22, 389-442.

Sanes, J. R. and Yamagata, M. (2009). Many paths to synaptic specificity. Annu. Rev. Cell Dev. Biol. 25, 161-195.

Schiaffino, S. and Reggiani, C. (1996). Molecular diversity of myofibrillar proteins: gene regulation and functional significance. Physiol. Rev. 76, $371-$ 423.

Sheard, P. W., Oettli, H. E., Johnson, A. J. and Duxson, M. J. (1997). Variations in oxidative enzyme type profiles among prenatal rat lumbar motoneurons. Brain Res. Dev. Brain Res. 103, 67-75

Takamori, S., Holt, M., Stenius, K., Lemke, E. A., Gronborg, M., Riedel, D., Urlaub, H., Schenck, S., Brugger, B., Ringler, P. et al. (2006). Molecular anatomy of a trafficking organelle. Cell 127, 831-846.
Talmadge, R. J., Otis, J. S., Rittler, M. R., Garcia, N. D., Spencer, S. R., Lees, S. J. and Naya, F. J. (2004). Calcineurin activation influences muscle phenotype in a muscle-specific fashion. BMC Cell Biol. 5, 28.

Wada, M. and Pette, D. (1993). Relationships between alkali light-chain complement and myosin heavy-chain isoforms in single fast-twitch fibers of rat and rabbit. Eur. J. Biochem. 214, 157-161.

Westgaard, R. H. and Lomo, T. (1988). Control of contractile properties within adaptive ranges by patterns of impulse activity in the rat. J. Neurosci. 8, 44154426.

Wigmore, P. M. and Evans, D. J. (2002). Molecular and cellular mechanisms involved in the generation of fiber diversity during myogenesis. Int. Rev. Cytol. 216, 175-232.

Windisch, A., Gundersen, K., Szabolcs, M. J., Gruber, H. and Lomo, T. (1998). Fast to slow transformation of denervated and electrically stimulated rat muscle. J. Physiol. 510, 623-632.

Yamagata, M., Weiner, J. A. and Sanes, J. R. (2002). Sidekicks: synaptic adhesion molecules that promote lamina-specific connectivity in the retina. Cell $110,649-660$.

Zengel, J. E., Reid, S. A., Sypert, G. W. and Munson, J. B. (1985). Membrane electrical properties and prediction of motor-unit type of medial gastrocnemius motoneurons in the cat. J. Neurophysiol. 53, 1323-1344.

Zweifel, L. S., Kuruvilla, R. and Ginty, D. D. (2005). Functions and mechanisms of retrograde neurotrophin signalling. Nat. Rev. Neurosci. 6, 615-625. 